\title{
O PARADOXO DA ESQUERDA NO BRASIL'
}

Luiz CARLOS BRESSER-PEREIRA

\section{RESUMO}

A esquerda costuma vencer as eleições no Brasil, mas não governa. Para sustentar o argumento, este artigo repassa os conceitos de direita e esquerda, definindo os grupos políticos de esquerda pela disposição a arriscar a ordem em nome da justiça social. Em segundo lugar, argumenta que, nas democracias modernas, não há inconsistência entre uma coalizão de esquerda e o capitalismo. Por fim, mostra como na experiência brasileira a esquerda de fato vence as eleições, mas não governa.

PALAVRAS-CHAVE: partidos políticos; esquerda; democracia moderna; sociedade civil.

\section{SUMMARY}

The left usually wins elections in Brazil but eventually does not govern. In order to validate this claim, the paper, first, reviews the concept of left and right, defining the left political groups by their disposition to risk social order in the name of social justice. Second, the paper argues that in modern democracies there is no inconsistency between a left coalition and capitalism. Third, it says that in Brazil the experience shows that the left indeed wins elections but does not govern.

KEYWORDS: political parties; left; modern democracy; civil society.

[1] Trabalho apresentado na conferência "A Esquerda na América Latina", organizada pelo Instituto Universitário de Investigação Ortega y Gasset, com a colaboração da Fundação Friedrich Ebert e da Fundação Pablo Iglesias. Madri, 28-29 nov. 2005.
A idéia de esquerda, como todas as demais idéias e instituições na América Latina, é transplantada e em grande parte inautêntica. Não obstante, é um fenômeno real, na medida em que é sempre possível distinguir a esquerda da direita em países capitalistas e democráticos. No caso do Brasil, objeto deste trabalho, a esquerda é uma realidade tão viva e poderosa que se justifica a questão central que quero responder aqui: por que a esquerda no Brasil ganha as eleições mas não governa? Este trabalho gira em torno dessa questão - que pressupõe um conceito amplo de esquerda - e do problema relacionado: existe uma especificidade para a esquerda na América Latina e, especificamente, no Brasil? Em que ela se distingue ou deve se distinguir da esquerda na Europa, que sempre lhe serviu de parâmetro, para poder ser autêntica e ter condições de governar? 
Essas questões não têm respostas unívocas. Estamos no campo minado das ideologias, no qual é preciso combinar o método históricodedutivo da boa ciência social com o método normativo da teoria política. Espero, entretanto, conseguir dar uma resposta que nos ajude a compreender a dinâmica e as crises da esquerda no Brasil. Uma resposta que seja aberta o suficiente para poder abrigar uma realidade tão complexa e, ao mesmo tempo, precisa a ponto de não se constituir em mero rol de lugares-comuns.

Para responder à primeira questão, terei que definir esquerda e direita. E justificar por que não trabalho com o conceito de centro, pressupondo que uma pessoa ou um partido é de esquerda ou de direita. Isso não significa que não admita as situações ambíguas, e sim que não quero me perder nelas. Em segundo lugar, terei que mostrar que a esquerda quase sempre ganha as eleições no Brasil, desde a transição democrática de 1985 . Em seguida, terei que explicar por que a esquerda ganha as eleições mas o governo que se forma afinal não é de esquerda, não representa os interesses dos pobres. Para isso, precisarei de duas coisas: do conceito de sociedade civil, que, no Brasil e nos demais países da América Latina, diverge, muito mais do que em países desenvolvidos, do conjunto dos eleitores votantes, que chamarei de povo; e de um entendimento maior do que sejam efetivamente esquerda e direita na região ou no Brasil.

\section{ESQUERDA E DIREITA}

Há alguns anos venho propondo um conceito geral de esquerda e direita que reproduzirei aqui. Esse conceito supõe que o objetivo político das sociedades modernas é a ordem ou segurança, a liberdade, o bem-estar, a justiça e a proteção da natureza ou do meio ambiente. A esquerda não se distingue da direita em termos de liberdade ou de promoção do bem-estar através do desenvolvimento econômico. Ainda que a liberdade política tenha sido originalmente uma conquista da burguesia, que fez uso da ideologia do liberalismo, a democracia foi, antes que qualquer outra coisa, uma conquista dos pobres e das classes médias, que durante o século XIX lutaram com os liberais para obter o sufrágio universal. No entanto, embora uma parte da esquerda - a utópica desdenhe o desenvolvimento econômico, que considera assegurado pelo capitalismo, quando partidos ou coalizões de esquerda chegaram ao poder na Europa revelaram-se tão interessados e capazes de promover o desenvolvimento econômico quanto partidos e coalizões de direita.Já em relação a ordem, justiça e proteção do ambiente, as diferenças são claras. São tão claras que possibilitam a seguinte definição de esquerda e direita. A direita é o conjunto de forças políticas que, em um país capitalista e democrático, luta sobretudo por assegurar a ordem, dando prioridade a esse objetivo, enquanto a esquerda reúne aqueles que estão dispostos, até certo ponto, a arriscar a ordem em nome da justiça - ou em nome da justiça e da proteção ambiental, que só na segunda 
[2] Bresser-Pereira, Luiz Carlos. "Por um partido democrático, de esquerda e contemporâneo". Lua Nova-Revista de Cultura e Política, no 39, 1997, pp. 53-71; e "A nova esquerda: uma visão a partir do Sul". Revista de Filosofia Política - Nova Série, vol.6, 2000. Porto Alegre: Universidade Federal do Rio Grande do Sul, Departamento de Filosofia, pp. 46-52. No segundo trabalho, desenvolvi mais extensamente esse conceito, contrastando-o com o de Bobbio (Bobbio, Norberto. Destra e sinistra. Roma: Donzelli Editore, 1994. Existe tradução para o português.)

[3] Sader, Emir.O anjo torto: esquerda (e direita) no Brasil. São Paulo: Editora Brasiliense, 1995, p. 164. metade do século XX assumiu estatuto de objetivo político fundamental das sociedades modernas ${ }^{2}$.

Adicionalmente, a esquerda se caracteriza por atribuir ao Estado papel ativo na redução da injustiça social ou da desigualdade, enquanto a direita, percebendo que o Estado, ao se democratizar, foi saindo do controle, defende um papel do Estado mínimo, limitado à garantia da ordem pública, dando preponderância absoluta para o mercado na coordenação da vida social. Porém, em relação ao Estado, há divergências dentro da própria direita, porque a experiência histórica mostra que apenas quando há forte aliança dos empresários com a burocracia do Estado se consubstancia uma estratégia nacional de desenvolvimento. Por sua vez, por muito tempo a esquerda rejeitou o Estado, que para Marx seria "o comitê executivo da burguesia", e para os anarquistas, o mal maior. No entanto, a experiência histórica demonstrou que nas democracias o Estado foi deixando de representar apenas os interesses da classe dominante para transformar-se em principal instrumento de ação coletiva à disposição da sociedade. Enquanto no processo histórico o capitalismo se revelava, a um só tempo, um regime injusto e corrupto - mas o único sistema econômico viável porque relativamente eficiente - , a democracia se revelava o instrumento por excelência através do qual as sociedades modernas domavam esse capitalismo: tornavam-no menos injusto e menos corrupto. Por isso, a esquerda reconciliou-se com o Estado, tornando-se prioritário para ela, nos termos de Sader, "a deslocação da polarização neoliberal entre estatal/privado para a construção do caráter público do Estado brasileiro"3. Quanto mais democrático se torna o governo do Estado, mais público ele se torna, ou seja, atende mais às demandas dos cidadãos e menos às das minorias poderosas.

Embora a defesa da intervenção do Estado regulando e corrigindo o capitalismo seja importante na distinção entre direita e esquerda, o elemento central dessa definição está na oposição entre ordem e justiça social. A proteção do meio ambiente é também cada vez mais importante, na medida em que os grupos políticos que adotam essa posição sejam em geral também mais de esquerda que de direita. Já os outros dois objetivos políticos centrais das sociedades modernas (a liberdadee o bem-estar) não distinguem historicamente a esquerda da direita, já que, no passado, tivemos a defesa ardorosa da liberdade e a competência em promover o bem-estar dos cidadãos partindo de governos de esquerda e de direita, como tivemos a violência contra a democracia e a incompetência em promover o desenvolvimento econômico originando-se em partidos políticos com as duas orientações. Quando, porém, se trata da ordem, o verdadeiro conservador não hesita, e lhe dá sempre prioridade sobre a igualdade, que, para ele muitas vezes nem sequer é um valor significativo. Já o verdadeiro progressista também preza a ordem, a segurança, contudo sabe que o progresso social envolve liberdade de protesto por parte dos mais pobres, dos que de alguma forma se sentem oprimidos - o que implica certo risco para a ordem. $O$ 
conservador afirma em qualquer hipótese o primado da lei; o progressista reconhece a necessidade do estado de direito, mas sabe também que a lei é com freqüência feita para defender os pobres contra os ricose que aqueles muitas vezes não têm alternativa para se fazer ouvir senão enfrentar a lei. A democracia é o regime da ordem, da lei e do compromisso, porém é também o regime do conflito social e da argumentação. A esquerda sabe que entre justiça e ordem existe uma contradição que os regimes democráticos devem, em princípio, ajudar a resolver. Enquanto a direita busca sempre que possível negar essa contradição na medida em que o estado de direito ou o império da lei tem absoluta precedência sobre a justiça, para a esquerda a lei muitas vezes representa o status quo, portanto os interesses dos ricos, e por isso precisa ser mudada a partir da pressão dos movimentos sociais, os quais, por falta de alternativa, nem sempre usam de meios puramente legais para exercer essa pressão. Já para a direita essa forma de arriscar a ordem ou a lei é inaceitável.

Em toda parte, inclusive no Brasil, a esquerda enfrenta uma contradição básica:enquanto a direita representa claramente os interesses dos ricos, principais defensores da ordem, a esquerda em princípio deveria representar os interesses dos pobres ou dos trabalhadores, mas na prática muitas vezes representa também os interesses das classes médias profissionais ligadas ao Estado. Existe aí um problema sério, porque, por mais que procure identificar-se com os pobres que pretende informalmente representar, essa classe média acaba representando também seus próprios interesses. $\mathrm{O}$ fato de esquerda e direita representarem interesses de classe é inevitável e até desejável, desde que essa representação não seja meramente corporativa - ou seja, desde que o político não suponha que seu papel é o de apenas representar os interesses dos que o apóiam ou o elegem. Nos países mais avançados politicamente, esse corporativismo é contrabalançado pelo espírito republicano dos cidadãos e dos políticos, que logram, até certo ponto, agir em função de suas convicções sobre o que seja o interesse público, mesmo quando isso colide com seus interesses pessoais.

A definição que acabei de apresentar para direita e esquerda é uma definição histórica; parte da observação empírica do comportamento efetivo dos grupos políticos identificados como esquerda ou direita. Em uma definição desse tipo, não seria necessário acrescentar que a esquerda defende na teoria o socialismo e na prática o estatismo, enquanto a direita defende o capitalismo? Sim, mas com restrições. O socialismo foi por muito tempo uma utopia da esquerda, porém quando esta se viu no poder, como aconteceu depois da Revolução Comunista de 1917, o sistema econômico afinal estabelecido foi o estatismo, não o socialismo. Por quê? Porque a sociedade russa estava longe de ter a igualdade de conhecimentos necessária para poder implantar com êxito um regime socialista. Essa é a contradição central da revolução socialista: busca a igualdade, mas para alcançá-la precisa que a igualdade, pelo menos de conhecimentos ou capacidades, já 
[4] Whitaker, Chico. O desafio do Fórum Mundial. São Paulo: Editora Perseu Abramo, 2005, pp. 15 e 19. Ver também Aguiton, Christophe et al. Où va le mouvement altermondialisation? Paris: La Découverte, 2003 e Fougier, Eddy. Altermondialisme, le nouveau mouvement d'emancipation? Paris: Liges de Repères, 2004. esteja razoavelmente implantada. Mesmo os países hoje mais desenvolvidos e com trabalhadores mais educados, teriam dificuldade em estabelecer um regime socialista, porque as diferenças de educação e competência técnica e organizacional entre os cidadãos continuam muito grandes. O que dizer de uma sociedade atrasada como era a russa e todas as demais que realizaram revoluções que se pretendiam socialistas? Estabeleceu-se ali, portanto, não o socialismo, mas o estatismo. Este teve êxito em promover a industrialização pesada a partir de forte acumulação forçada de poupanças, porém afinal revelou sua incapacidade econômica de competir com o capitalismo. Dessa forma, o ideal socialista continua a ser um ideal das esquerdas, mas a centroesquerda em especial, ou esquerda moderada, limita-se a pensar nele como utopia e trata de promover de forma reformista a justiça e a defesa do meio ambiente no capitalismo.

Há muitos tipos de esquerda, mais que de direita, provavelmente porque esta, além dos valores e idéias, tem o capital a uni-la, enquanto a esquerda só tem valores e idéias. Podemos distinguir pelo menos quatro tipos de esquerda: a extrema esquerda, a esquerda utópica, a esquerda burocrático-sindical, e a centro-esquerda.

A extrema esquerda é revolucionária, não vê na democracia existente senão uma forma de dominação: pretende assumir o poder revolucionariamente para, em seguida, implementar o que denomina socialismo o que seria mais correto chamar de estatismo.

A esquerda utópica prefere não disputar o poder para manter seus ideais socialistas e para poder ser uma força crítica dentro da sociedade. Nos dias atuais, esseé o caso, em especial, do extraordinário movimento "outromundialista", que se formou a partir dos encontros do Fórum Social Mundial. Seus participantes mais representativos afirmam que não aspiram ao poder, mas querem ser a consciência crítica das sociedades capitalistas contemporâneas, e querem "contribuir para que a sociedade faça prevalecer, em toda parte, a justiça social, a solidariedade e a paz", ou, em outras palavras, "um outro mundo possível"4. Esse objetivo é sem dúvida legítimo, e o movimento já tem dado contribuições positivas na direção pretendida, na medida em que a enorme repercussão de suas ações tem obrigado os governantes conservadores ou progressistas a mudar algo de suas políticas.

A esquerda burocrático-sindical joga o jogo democrático, tem bases fortes na burocracia do Estado e nos sindicatos, se autodenomina esquerda simplesmentee, enquanto fora do poder, mantém um discurso formalmente socialista.

A centro-esquerda reconhece a impossibilidade de transição para o socialismo dentro de um prazo previsível e, usando uma frase de Michel Rocard, trata de "governar o capitalismo mais competentemente que os capitalistas". Ou seja,éuma esquerda reformista, que durante o séculoXX foi social-democrata, mas está se transformando em centro-esquerda social-liberal, na medida em que os partidos de esquerda na Europa vêm 
reformando suas economias e seu Estado no sentido de manter a garantia aos direitos sociais e aprofundar a igualdade, ao mesmo tempo que aceitam um papel mais ativo de mercados regulados na coordenação do sistema. O social-liberalismo representa uma superação positiva da social-democracia; entretanto, da mesma forma que a social-democracia foi por muito tempo acusada de trair os ideais do socialismo revolucionário, agora se acusa o social-liberalismo de trair os ideais da social-democracia. Hoje, os países que apresentam governos de esquerda mais bemsucedidos - caso dos escandinavos, da Holanda e da Grã-Bretanha estão deixando de ser social-democratas para ser social-liberais.A principal mudança é a reforma da gestão pública, auxiliada por organizações de serviço públicas não estatais na realização, de forma competitiva, de serviços sociais e científicos. Com isso, o Estado diminui o número de servidores, mantendo dentro de seu aparelho apenas servidores de alto nível e prestígio. A despesa pública em relação ao Produto Interno Bruto (PIB) se mantém elevada, mas, paralelamente, aumenta de modo substancial a eficiência dos serviços prestados pelo Estado, eos direitos sociais passam a ser mais respeitados, devido à melhoria da quantidade e da qualidade dos serviços ${ }^{5}$. Embora prestigie os altos servidores públicos, essa perspectiva de reforma da gestão pública não tem espaço para servidores de nível médio e baixo, ou para quem não realiza atividades específicas de Estado. Não é surpreendente, por isso mesmo, que encontre forte oposição da esquerda burocrático-sindical.

Entre a extrema esquerda e centro-esquerda há, naturalmente, uma gradação de posições saindo do discurso da revolução para o da reforma social. Poderíamos chamar apenas de esquerda a posição intermediária, cara aos intelectuais: uma esquerda que não faz compromissos nem com a burguesia nem com a burocracia. Essa esquerda, porém, não existe no plano político: só idealmente. No Brasil, um de seus principais intérpretes é Emir Sader, que, em vez de opor justiça social a ordem, define a esquerda pela oposição entre justiça e neoliberalismo. "No Brasil", diz ele, "ser de esquerda significa a contraposição ao neoliberalismo." Essaé uma definição correta, porqueé por meio do neoliberalismo que a ordem se manifesta hoje, embora haja um número razoável de conservadores que também se opõem a ele. No entanto, o problema da revolução socialista é evitado com a idéia de que "ser de esquerda no mundo de hoje significa participar de forma concreta de uma nova sociedade"6. Quando, entretanto, se procura saber o conteúdo dessa nova sociedade, verificamos que esse projeto não existe, porque seus propugnadores sabem não poder ser socialistas mas não querem admitir o capitalismo reformado. Como fica claro em uma obra posterior de Sader, o mais importante seriam mudanças na política econômica. Segundo o autor, essa nova sociedade teria como pilares a renegociação da dívida externa, a renegociação da dívida pública e políticas econômicas que privilegiam a distribuição de renda7. Em que pesem minhas ressalvas pessoais em relação a essas políticas ${ }^{8}$, é importante assinalar aqui que elas não levam a uma
[5] Expus mais amplamente o conceito de social-liberalismo, aplicado sobretudo à reforma do Estado, em Democracy and public management reform: building the Republican state. Oxford: Oxford University Press, 2004. A França e a Alemanha continuam resistindo à reforma da gestão pública, presos que estão ao modelo burocrático clássico. Essa é uma explicação importante para o mal desempenho econômico desses países nos últimos dez anos.

[6] Sader, Emir. O anjo torto, p. 194.

[7] Sader, Emir. A vingança da história. São Paulo: Boitempo Editorial, 2003, pp. 175-76.

[8] Embora profundas modificações sejam necessárias na política econômica do governo, não se justifica o calote, tanto da dívida externa como da interna. Mais importante é reduzir drasticamente a escandalosa taxa de juros Selic (o que importaria em redução do valor presente da 
dívida), e adotar uma nova política de proteção ao capital e ao trabalho nacionais, interrompendo a absurda abertura financeira do Brasil ao capital externo. "nova sociedade": apenas buscam reformar de maneira muito modesta o capitalismo. Não há, portanto, razão prática para no plano ideológico - aquele em que nossa discussão está inserida - distinguir esquerda de centro-esquerda, a não ser que quiséssemos incluir entre os critérios de distinção competência ou propriedade das políticas econômicas sugeridas - o que não é o caso.

\section{INEXISTENTE, MAS FUNDAMENTAL}

Na discussão do conceito de esquerda,éessencial debater o problema do centro - ou, mais especificamente, do centro que se move. No meu entender, no quadro das sociedades modernas, não existem agrupamentos políticos de centro. Aqueles que assim se autodenominam são sempre de direita. Na verdade, alguém ou algum grupo oué de esquerda ou de direita. Podemos e devemos transformar essa dicotomia em uma escala ideológica que vai da extrema direita para a estrema-esquerda, passando por direita, centro-direita, centro-esquerda e esquerda. Ficamos, assim, com uma escala de seis formações políticas, porém sem um centro. Nessa escala, o centro éinexistente: alguém ou algum grupo ou é de esquerda ou de direita.É inexistente, mas, como ponto virtual, é fundamental. Porque essecentro se move de modo cíclico ora para um lado ora para outro, e porque toda a luta ideológica entre esquerda e direita nas democracias modernas se trava em torno da questão de empurrar essecentro mais para a esquerda ou mais para a direita.

O que vimos no mundo, desde meados dos anos 1970, foi o êxito da direita em mover o centro para a direita, com a ofensiva ideológica neoliberal. Nos anos 1990, diante do fracasso parcial das reformas e promessas da direita, iniciou-se um movimento do centro para a esquerda, mas a eleição infausta e controvertida de um presidente conservador no país dominante, os Estados Unidos, interrompeu esse processo. $\mathrm{Na}$ América Latina, porém, na qual o fracasso das reformas neoliberais foi radical, continua o movimento do centro para a esquerda. Isso aconteceu porque algumas dessas reformas, em especial a abertura financeira, além de serem concentradoras de renda, revelaram-se contrárias aos interesses nacionais do desenvolvimento econômico. O enorme desenvolvimento dos países asiáticos - que, embora comprometidos com o desenvolvimento capitalista, rejeitaram as reformas propostas ou pressionadas a partir do Norte - vem aprofundando esse movimento dos países latino-americanos para a esquerda, não obstante a hegemonia dos Estados Unidos sobre a região.

O centro inexistente - ou, para ser mais preciso, apenas existente como realidade virtual, como ponto de referência a dividir a esquerda da direita -é, assim, paradoxalmente todo-poderoso, porque a luta político-ideológica nas democracias modernas diz respeito a ele. Os movimentos do centro são pendulares: ora o centro caminha para a esquerda, como aconteceu no mundo a partir da Grande Depressão dos anos 1930 , 
ora caminha para a direita, como ocorreu a partir de meados dos anos 1970. Esses movimentos ocorrem na medida em que se esgotam as propostas de governo de um ou outro grupo e os eleitores situados mais ao centro deslocam-se na direção oposta à dominante.

Contudo é preciso considerar que o centro varia geograficamente. Nos Estados Unidos, onde nunca houve um movimento socialista forte, o centro está muito mais à direita que na Grã-Bretanha, a qual por sua vez está mais à direita que a França, a Alemanha, ou a Espanha. Essa diferença geográfica de posição do centro se deve a razões de ordem histórica, que não importa discutir aqui. O importante é deixar claro que, se aceitarmos essa variação no centro, o conceito de esquerda e direita torna-se relativo. Políticas consideradas de esquerda nos Estados Unidos poderão ser consideradas de direita na França. Os políticos progressistas ou de esquerda americanos são em geral associados ao Partido Democrata, e denominados liberais, numa referência ao século XVIII e começo do XIX, quando os liberais eram progressistas lutando em nome da burguesia, contra conservadores ainda aliados à aristocracia.

Ainda convém assinalar que, ao afirmar que o centro se move no tempo e que varia de país para país, reconheço uma limitação na definição teórica que ofereci no início. Se for estrito em definir esquerda e direita em relação a ordem e justiça, não faria sentido essa variação. Seria sempre de esquerda arriscar a ordem, admitir a ação de movimentos sociais (como greves), restringir sem violência ações ilegais de outros movimentos sociais (como as invasões que, no Brasil, os sem-terra e os sem-teto com freqüência promovem) e apoiar suas reivindicações. Em contrapartida, defender a lei a qualquer preço, usar da autoridade tradicional e religiosa para justificar posições políticas e morais seria sempre de direita. Isso, porém, é verdadeiro até certo ponto. Nas questões sociais, o princípio da razoabilidade deve prevalecer sempre, e esse princípio rejeita distinções claras e precisas entre branco e preto. A realidade social é ambígua. A direita tende a pressupor que o ser humano é, por natureza, egoísta ou auto-interessado; a esquerda, a pensá-lo como generoso ou capaz de generosidade. $\mathrm{Na}$ verdade, o ser humano é intrinsecamente contraditório e, portanto, ambíguo. Ele nasce com duas necessidades fundamentais e contraditórias: de um lado, o instinto da sobrevivência o faz individualista e egoísta; de outro, o instinto da convivência o torna solidário e cooperativo. Toda a sociedade humana está baseada nessa ambigüidade, por isso os cientistas sociais enfrentam tanta dificuldade em prever seu comportamento.

\section{ESQUERDA E NAÇÃO}

O interesse e a capacidade de promover o desenvolvimento econômico, assim como a liberdade, não distinguem a esquerda da direita. É natural que cada um dos agrupamentos políticos afirme ser mais capaz 
de uma coisa ou de outra, mas vimos historicamente governos de direita e de esquerda sendo bem-sucedidos e desastrosos em relação a esses dois objetivos políticos. Entretanto, nesta seção argumentarei que, quando se pensa na definição de esquerda em países em desenvolvimento, seria preciso incluir a idéia de desenvolvimento como objetivo básico e a idéia de nação como objetivo para o desenvolvimento. Historicamente, na Europa do século XIX e de Marx, a burguesia era nacionalista e a esquerda, internacionalista. O internacionalismo da Internacional Socialista, porém, nunca convenceu os trabalhadores, que não hesitaram em de alguma forma associar-se à burguesia e aos técnicos do governo quando se tratava de competir internacionalmente. Foi isso que permitiu que todos os países capitalistas bem-sucedidos no plano econômico consolidassem ao mesmo tempo o projeto de construção de seus Estados-Nações. Uma Nação só ganha coesão e força, e o Estado só se torna instrumento de ação coletiva dessa Nação, se as classes sociais, não obstante os conflitos, são capazes de tornar-se solidárias quando se trata de competir com outras nações. No momento, porém, em que a construção nacional e o desenvolvimento se consolidaram naqueles países do Norte, o nacionalismo deixou de ser uma ideologia expressa para tornar-se subentendida. O nacionalismo é a ideologia da construção do Estado-Nação, é o princípio básico que alimenta as relações internacionais tanto na fase da Diplomacia do Equilíbrio de Poderes como na fase da Política do Sistema Global, e é a afirmação da prioridade dos interesses nacionais em relação aos demais países vistos como competidores. Na prática, implica atribuir aos governos a responsabilidade de defender o trabalho, o conhecimento e o capital nacionais. Hoje, nesses países, como nos países dinâmicos da Ásia - muito diferentemente do que acontece nos países dependentes da América Latina - quase ninguém tem dúvida de que esse é o dever de seus governos, de forma que se tornou desnecessário reafirmar o próprio nacionalismo, transformado em valor consensual. Tornou-se, então, possível ocultar essa perspectiva, sempre incômoda nas relações internacionais, e reservar o adjetivo nacionalista para as perversões do nacionalismo, para suas expressões extremadas e violentas como o nazismo, ou para formas de populismo de direita e de esquerda em países em desenvolvimento. Para os países ricos, esse ocultamento tem a vantagem não prevista de neutralizar o eventual nacionalismo dos países em desenvolvimento, tornando suas elites mais dóceis às diretrizes vindas do Norte, sobretudo às políticas de seu interesse econômico.

Diante desse quadro, a esquerda nos países em desenvolvimento não pode reproduzir dos países ricos nem o discurso sobre nacionalismo, nem o discurso da esquerda. O motivo não é apenas o nível de desenvolvimento econômico e político, menor que o da França, Alemanha ou Grã-Bretanha. É preciso não esquecer que o Brasil, embora apresente uma sociedade dual e, portanto, uma economia subdesenvolvida, jáé uma sociedade capitalista moderna. Porém,é preciso também consi- 
derar que os países de desenvolvimento médio não lograrão evitar a dominação vinda do Norte, se não adotarem as políticas e instituições necessárias para seu desenvolvimento. Nos últimos vinte anos, enquanto os países asiáticos dinâmicos continuavam a usar do nacionalismo para construir seus Estados nacionais e para promover com êxito seu desenvolvimento, os países latino-americanos - que entre os anos 1930 e 1980 estavam realizando suas revoluções nacionais - viram essa construção ser interrompida9. Nos últimos vinte anos, a nação brasileira, a partir da crise da dívida externa transformada em crise fiscal do Estado e em inflação alta, perdeu autonomia real e voltou à condição semicolonial, enquanto era submetida à onda ideológica neoliberal e globalista vinda do Norte. Isso ocorreu porque o antigo modelo nacional-desenvolvimentista, bem-sucedido em promover a industrialização do país entre 1930 e 1980, entrou em crise. Ocorreu também porque a pressão ideológica globalista vinda do Norte - a qual afirmava que na era da globalização o Estado-Nação perdera relevância e anunciava a governança global em um mundo sem fronteiras - tornou-se fortíssima a partir daquela mesma data. E ocorreu, finalmente, porque as elites brasileiras conservadoras e dependentes, sobretudo aquelas ligadas ao setor financeiro, aderiram rápido às novas idéias.

Nesses termos, seria razoável esperar que, nos países latino-americanos, a esquerda fosse nacionalista e tivesse como prioridade o desenvolvimento econômico. No Brasil, isso aconteceu quando os grupos de esquerda mais representativos afinal se associaram aos empresários industriais no pacto nacional-desenvolvimentista de Vargas e Kubitschek (1930-60). Na América Latina, porém, a esquerda deixou de ser nacionalista desde que os empresários apoiaram os golpes militares no Cone Sul.A adoção da "teoria da dependência", seja na versão marxista, seja na versão da "dependência associada", não foi motivo para que a esquerda se tornasse mais nacionalista, como se poderia imaginar; pelo contrário, fez com que copiasse a clássica perspectiva internacionalista da esquerda européia do século XIX. Partindo do pressuposto de que não seria possível haver um empresariado nacional na América Latina, a primeira versão da teoria da dependência concluiu pela revolução socialista, e a segunda pela associação com os países ricos ${ }^{10}$. Contudo, a prioridade dada ao desenvolvimento econômico foi abandonada pela esquerda; na medida em que ela assumiu que no capitalismo o desenvolvimento ocorreria de qualquer maneira, de forma a caber-lhe a preocupação com a democracia e a justiça social. Entretanto, embora seja verdade que, para os países que completaram sua revolução industrial, o desenvolvimento capitalista tenda a ser auto-sustentado ${ }^{11}$, isso não é verdade para os demais, submetidos a processos de imperialismo. Nesse caso, suas elites se tornaram ambíguas em relação aos interesses nacionais, porque ao mesmo tempo que se identificavam com esses interesses, eram ideologicamente dependentes do centro desenvolvido ${ }^{12}$. Esse tipo de consciência, porém, não ocorreu nas esquerdas latino-americanas e
[9] Furtado, Celso. Brasil: a construção interrompida. São Paulo: Editora Paz e Terra, 1992.

[10] Bresser-Pereira, Luiz Carlos. "Do Iseb e da Cepal à teoria da dependência". In Toledo, Caio Navarro de (org.), 50 anos do ISEB. São Paulo: Editora da Unesp, 2005.

[11] Furtado, Celso. "O processo histórico do desenvolvimento". Indesenvolvimento e subdesenvolvimento. Rio de Janeiro: Editora Fundo de Cultura, 1961. Republicado em Bresser-Pereira, Luiz Carlos e Rego, José Márcio (orgs.). A grande esperança em Celso Furtado. São Paulo: Editora 34, 2002.

[12] Em "Do Isebeda Cepalà teoria da dependência” chamei essa dependência não de "associada", nem de contrapartida da "superexploração imperialista", mas de "nacional-dependente" -oximoro que salienta o caráter contraditório das elites empresariais e intelectuais em países dependentes como o Brasil. 
[13] Lozano, Wilfredo. "La izquierda latinoamericana en el poder". Nueva Sociedad, no 197, 2005, p. 145 .

[14] Dimoser, Ditmar. "Democracia sin democratas: sobre la crisis de la democracia en América Latina". Nueva Sociedad, no 197, 2005, p. 40. brasileiras, cujos intelectuais são também dependentes. Fizeram, portanto, o queéinerente à situação de dependência não criticada:copiaram o internacionalismo das esquerdas européias, não se dando conta de que elas só adotaram o internacionalismo em teoria, enquanto se associavam aos empresários na construção da nação e na participação em estratégias nacionais de desenvolvimento.

\section{O PARAdoXo da Esquerda}

Se o centro varia geograficamente, seria interessante perguntar o que acontece com o centro no Brasil ou na América Latina. Está mais à esquerda ou mais à direita do que nos países desenvolvidos da Europa continental? Não sei responder com clareza, porque a divisão entre esquerda e direita enfrenta uma dificuldade fundamental na região. Não quero falar por toda a América Latina, onde a esquerda hoje está presente no governo da Argentina, do Uruguai, do Chile, da Venezuela e do Brasil. Conforme observou Wilfredo Lozano, "a esquerda hoje no poder resulta ser um complexo produto de sua reacomodação reformadora, o que a obrigou a girar para o centro"13. Quanto, entretanto, girar para o centro? E o giro é apenas para o centro ou para a direita? Ditmar Dimoser, em texto sobre a democracia na América Latina, pergunta "estará o futuro latinoamericano caracterizado por democracias sem democratas?"14. Tal pergunta envolve um paradoxo absoluto. No caso do Brasil, não em relação à democracia mas sim à esquerda, a questão está dominada por outro paradoxo, que talvez não esteja ausente do restante da América Latina: a esquerda ganha as eleições, na medida em que partidos de esquerda ou de centro-esquerda alcançam a maioria no Parlamento, porém não governa. Proponho denominaressefenômeno de "paradoxo da esquerda". Será ele verdadeiro? Se for, há uma explicação ou é um paradoxo puro?

\section{Tabela 1}

Deputados federais eleitos - (1986-2002)

\begin{tabular}{c|c|c}
\hline ANO & $\begin{array}{c}\text { Esquerda } \\
(\%)\end{array}$ & $\begin{array}{c}\text { Direita } \\
(\%)\end{array}$ \\
\cline { 2 - 3 } 1986 & 63,0 & 37,0 \\
1990 & 48,9 & 51,1 \\
1994 & 54,6 & 45,4 \\
1998 & 57,5 & 42,5 \\
2002 & 60,6 & 39,4 \\
\hline
\end{tabular}

Nota: Partidos considerados de esquerda: PT, PSDB, PMDB, PDT, PSB, PCB/PPS, PCdoB e PV; os demais foram considerados de direita.

Para responder a essas perguntas, parto do pressuposto de que a ideologia determina o voto no Brasil. Esse pressuposto teórico foi posto em dúvida por uma série de analistas internacionais, a maioria de filia- 
ção conservadora, que também tendem a negar a relevância da diferença entre esquerda edireita. Mas afinal as pesquisas deixaram claro que os eleitores - apesar da falta de estrutura ideológica definida, para a qual seriam necessários conhecimentos que eles não têm — possuem identificação ideológica suficiente que lhes permite distinguir as posições de esquerda ou de direita, progressistas ou conservadoras. Singer testou essa hipótese em relação ao Brasil, e a viu confirmada ${ }^{15}$. O Brasil transitou para a democracia em 1985. Desde então, conforme os dados da Tabela 1, os partidos que dominam o Parlamento brasileiro (por ordem histórica, PMDB, PSDB e PT) sempre se autodefiniram como partidos de esquerda - os dois primeiros de centro-esquerda, o último de esquerda - e, junto com os pequenos partidos de esquerda, lograram a maioria na Câmara dos Deputados ${ }^{16}$. Entre os três presidentes eleitos diretamente pelo povo desde 1985, dois se autodenominaram de esquerda, Fernando Henrique Cardoso e Luiz Inácio Lula da Silva, e apenas um aceitava ser de direita, Fernando Collor.Éverdade que nem todos os parlamentares desses partidos podem ser considerados de centroesquerda: depois que o PT se tornou governo, alguns petistas são antes de centro-direita, apesar dos programas e das mensagens políticas de centro-esquerda.

No Brasil, é evidente por que os partidos e os candidatos presidenciais de esquerda tendem a ser eleitos com mais freqüência do que os de direita. Está diretamente relacionado com a brutal desigualdade social existente no país. Essa desigualdade, somada aos baixos níveis de educação e de formação cívica do povo brasileiro, fazem-no esperar dos políticos um discurso voltado para melhor distribuição de renda. Os políticos de esquerda podem fazer isso de forma natural, sem necessariamente serem populistas; já os candidatos de direita só são capazes de formular um discurso dessa natureza sendo populistas. Os candidatos de direita que ganham eleições executivas no Brasil são quase sempre políticos populistas e demagógicos, com um discurso que não corresponde a suas convicções. Já os candidatos de esquerda podem ser mais autênticos, embora não estejam livres do populismo.

Entretanto, uma vez eleitos, nem o presidente nem os parlamentares de esquerda fazem um governo de esquerda, ou seja, que de fato contribua para reduzir a injustiça social no país. Podem incluir em suas administrações algumas políticas sociais redistributivas, atendendo assim à pressão dos pobres, mas afinal seus governos promoverão sobretudo os interesses dos ricos, e a renda e a riqueza se manterão concentradas. Isso foi possível observar no governo Sarney (1985-89), imediatamente após a transição democrática. O próprio presidente não era um político da esquerda, e sim um nacionalista populista que militou no partido do governo durante o regime militar; porém o Parlamento eleito em 1986 era dominado por políticos de centro-esquerda, que haviam se oposto ao regime militar. Não obstante, não há nada no governo Sarney que se possa identificar como de esquerda. Pelo contrário, nos últimos dois
[15] Singer, André. Esquerda e direita no eleitorado brasileiro. São Paulo: Edusp, 1999.

[16] Não lograram, todavia, maioria no Senado. 
[17] Esses funcionários haviam recebido o nome de marajás, e o candidato comprometeu-se habilmente a acabar com o privilégio. anos o governo caminhou para a direita:o presidente firmou acordo com um grande grupo conservador que se formou então no Congresso com o nome de Centrão.

O primeiro presidente eleito pelo voto popular foi Fernando Collor de Mello, em 1989. Era um político conservador. Mas é importante salientar que, mais que de direita, ele era um político populista. Isso porque logrou estabelecer contato direto com a população em nome da moralização da burocracia, especificamente dos salários abusivos de um certo número de altos funcionários, aproveitando-se da alta inflação em vigor desde 1980 e de falhas legais no sistema de correção monetária dos salários ${ }^{17}$. Sua mensagem moralista, entretanto, não impediu que ele próprio se envolvesse em corrupção, a ponto de, dois anos depois, ser afastado do governo mediante um processo de impedimento.

O próximo presidente eleito, Fernando Henrique Cardoso, tinha uma trajetória conhecida: inicialmente, como intelectual de esquerda; depois, como político de centro-esquerda. Provinha do PSDB, partido que se pretende socialdemocrata inclusive no nome: Partido da Social Democracia Brasileira. Foi eleito porque, como ministro da Fazenda no governo intermediário de Itamar Franco, logrou controlar a alta inflação brasileira com um plano de estabilização que neutralizava com competência a inércia inflacionária. Entretanto, seu governo foi antes e centrodireita que de esquerda. Foi de centro-esquerda na área social, na medida em que aumentou a carga tributária e gastou mais e com mais competência em educação, saúde, reforma agrária e assistência social. Mas seu governo acabou concentrando renda. Adotou uma política cambial que aprofundou a desnacionalização da economia brasileira e levou a duas crises de balanço de pagamentos. Adotou igualmente uma política monetária de elevadas taxas de juros do Banco Central (BC), a qual beneficiou os rentistas, ou seja, os que vivem de juros, e o sistema financeiro que recebe comissão dos rentistas.

Mais surpreendente é o governo de direita que vem fazendo o presidente Luiz Inácio Lula da Silva. Como o PT se declarava um partido claramente mais à esquerda do que o $\mathrm{PSDB}$, os mercados financeiros nacionais e internacionais pressupunham que sua eleição representasse uma clara guinada do Brasil para a esquerda. A segunda crise de balanço de pagamentos do governo Cardoso, em 2002, deveu-se em parte a essa desconfiança. Entretanto, o que se viu foi um governo que, embora conservasse suas alianças com o sindicalismo e movimentos sociais como o Movimento dos Trabalhadores Rurais Sem Terra (MST), revelou-se logo claramente de direita. Isso ficou bastante claro em relação à política monetária: o nível da taxa de juros básica do $\mathrm{BC}$, que já era a mais alta do mundo, aumentou ainda mais para satisfazer os rentistas. A taxa de juros real em 2005 foi em média de $12 \%$, quando o risco Brasil não justificava mais que $3 \%$. De um gasto com juros pelo setor público estimado em 160 bilhões de reais em 2005 , correspondendo a $8 \%$ do PIB, apenas 40 bilhões de reais são justificáveis: o restante é mera transferência aos 
credores do Estado brasileiro, que se tornou refém com a desculpa de que essa taxa é necessária para combater a inflação. Temos, assim, chancelada por um governo de esquerda, uma brutal transferência de renda dos pobres e da classe média, que pagam impostos (principalmente indiretos, no Brasil) para os ricos, que recebem juros e, no mercado financeiro, comissões. Além disso, a política social do governo não revelou inovações. O único gasto social que aumentou foi o assistencialista, com a substituição do Bolsa Escola, que exigia dos pais pobres que os filhos estivessem na escola, para o Bolsa Família. Ou seja, em vez de ênfase em políticas universalistas, que são de esquerda, adotou uma política conservadora de focalização. E afinal, no terceiro anodo mandato, tornou-se público que esse governo e o próprio PT, que durante anos insistira em seus padrões éticos, se envolvera em um processo sem precedentes de corrupção política, conhecido com o nome de "escândalo do mensalão". O PT pagava com dinheiro o apoio que recebia de deputados de outros partidos, financiando-se com recursos oriundos evidentemente de empresas beneficiadas pelo governo ${ }^{18}$. Em síntese, conforme observou Fernando Cardim de Carvalho em trabalho recente sobre a esquerda e a política econômica no Brasil, "o primeiro governo FHC foi quase a antítese do que seria esperado da passagem pelo poder de um partido autodenominado socialdemocrata" ${ }^{19}$. Porém "poucos discordariam da afirmação que o governo Lula não perseguiu nenhuma das prioridades que caracterizam qualquer governo de esquerda no século XX". Em outras palavras, foram governos eleitos pela esquerda, mas não foram governos de esquerda.

\section{GOVERNAR O CAPITALISMO}

Não tivemos, portanto, governos de esquerda no Brasil desde a transição democrática de 1985 , não obstante a maioria do eleitorado votasse em candidatos de esquerda. Antes de tentar explicar esse fato, porém, uma pergunta preliminaréessencial: pode a esquerda governar o capitalismo? É possível pensar em governos de esquerda governando um sistema econômico que em essência continua capitalista, ou seja, coordenado pelo mercado, e voltado para o lucro privado?

A resposta é positiva, se examinarmos a experiência de um semnúmero de governos de partidos ou coalizões de centro-esquerda na Europa desde a Segunda Guerra Mundial. Partidos que agem nos termos da definição de esquerda apresentada nas primeiras seções deste trabalho têm se revelado muitas vezes capazes de governaro capitalismo de forma mais competente que os capitalistas. São de esquerda porque buscam reformar esse capitalismo, porque procuram distribuir melhor a renda e caminhar na direção de maior igualdade de oportunidades, porque defendem maior liberdade individual nos quadros de uma sociedade mais solidária. São sempre partidos de centro-esquerda. Não existe a hipótese de um partido de extrema esquerda governar um país
[18] A imprensa tem feito ampla cobertura desse escândalo. Talvez a melhor reportagem até agora tenha sido feita por Norman Gall (“Lula e Mefistófoles". Braudel Papers, no 38,2005 , pp. 1-14). O governo Lula e o PT reconheceram as irregularidades, mas tentaram identificá-las com caixa dois em campanhas eleitorais, ou seja, com doações de dinheiro não declaradas ao fisco e aos tribunais eleitorais. Dessa forma, o PT estaria fazendo algo usual no processo de financiamento de campanhas eleitorais. Ao longo desse escândalo, porém, foi ficandoclaro que o processo envolvia corrupção stricto sensu, seja pela compra de votos de deputados de outros partidos, seja pelo fato de os recursos provirem de empresas estatais cujos contratos de publicidade eram sobrefaturados ou de fornecedores do Estado, que compensavam as doações com sobrefaturamento dos serviços. Além disso, não se tratava de simples financiamento de campanhas eleitorais, já que o sistema passou a fazer parte do governo federal, como antes fizera parte dos governos municipais em que o PT elegera o prefeito.

[19] Carvalho, Fernando J. Cardim. "FHC, Lula e a desconstrução da esquerda". Rio de Janeiro: Instituto de Economia da UFRJ, 2005, cópia, pp.10 e 15 . 
[20] Przeworski, Adam. Capitalism and social democracy. Cambridge: Cambridge University Press, 1985.

[21] As pesquisas de Lijphart (Lijphart, Arend. Patterns of democracy. New Haven: Yale University Press, 1999) e de Esping-Andersen (EspingAndersen, Gosta. The three worlds of welfare capitalism. Princeton, NJ: Princeton University Press, 1990) sobre modelos de democracia e de capitalismo são significativas nesse ponto. capitalista. Não conheço sequer uma experiência de tentativa desse tipo. O governo Allende, por exemplo, assim como muitos outros governos de esquerda derrubados por forças de direita nacionais e externas, não era um governo de extrema esquerda. Foi apenas um governo de esquerda que, não sabendo governar o capitalismo melhor que os capitalistas, cometeu erros que facilitaram a reação da direita e do imperialismo, e por fim o golpe sangrento.

Para governar o capitalismo melhor e com mais justiça que uma coalizão de direita, uma coalizão de esquerda precisa reconhecer a lei básica do capitalismo: a taxa de lucro dos empresários e dos capitalistas ativos deve ser mantida em nível satisfatório para que eles continuem a investir. Conforme observou Przeworski, os empresários têm o "poder de veto" sobre o sistema. ${ }^{20}$ Se deixam de investir, o crescimento econômico estanca e o país entra em crise. Por isso, é essencial algum tipo de associação com os empresários produtivos. Já os capitalistas rentistas, que no passado viviam de aluguéis e hoje vivem principalmente de juros pagos pelo governo, não podem ser aliados de um governo de esquerda. Também não pode ser aliada de uma coalizão de esquerda uma parte dos empresários produtivos que se recusam a fazer compromissos com os trabalhadores e as classes médias profissionais. Da mesma forma, não pode fazer parte do sistema de apoio a uma coalizão de esquerda o grupo de profissionais que, sabendo ser o capitalismo hoje o capitalismo do conhecimento ou dos técnicos, aproveita-se desse fato para obter ganhos extraordinários apoiados em seu conhecimento técnico. Não pode porque um governo só será de esquerda se, além de ser formado por políticos que se definem como de esquerda, lograr, ainda que marginalmente, desconcentrar a renda e a riqueza; transformar em realidade mais concreta a igualdade de direitos entre pobres e ricos, entre mulheres e homens, entre as diversas raças; avançar na implantação de maior igualdade de oportunidades de renda, poder e prestígio social; dar à democracia um caráter mais representativo e mais participativo. Não será possível ou realista esperar grandes ganhos nessa matéria, mas a experiência mostra que países governados mais longamente por coalizões de esquerda, assim como países nos quais o centro esteja mais à esquerda, alcançam níveis mais elevados de democracia e de justiça social. Não é por outra razão que o modelo capitalista existente nos países escandinavos é superior em termos de justiça e democracia, comparado aos países do modelo renano, o qual, por sua vez, é superior ao nível de justiça social e de democracia existente nos Estados Unidos. Não é fácil comprovar uma afirmação geral como essa, porém não é difícil chegar a essa conclusão quando se comparam, entre outros indicadores, os índices de violência e distribuição de renda, assim como as formas de financiamento de campanhas políticas ${ }^{21}$.

Sob essa perspectiva, merece citação especial a experiência recente de oito anos de governo trabalhista na Grã-Bretanha. Esse governo teve 
início com uma proposta de "terceira via"22 — nome inadequado para um conjunto de idéias concretas sobre como um governo de esquerda moderna pode governar o capitalismo de forma mais competente que os capitalistas. Embora essas idéias estivessem apoiadas em um sociólogo de esquerda de alto prestígio como Anthony Giddens, foram amplamente criticadas pelas esquerdas de outros países e mesmo da Grã-Bretanha ${ }^{23}$. Na Europa continental, sobretudo, duvidou-se de que fossem de fato idéias de esquerda, ignorando que na Grã-Bretanha o centro está mais à direita que no modelo renano da França e da Alemanha. Entretanto, a prova de qualquer coisa só pode ser empírica. Cabe, portanto, perguntar o que aconteceu naquele país depois de oito anos de governo trabalhista. Nesse período, que terminou com nova reeleição, os trabalhistas, apesar do apoio inconsiderado à trágica invasão americana do Iraque, foram bem-sucedidos em realizar um governo de esquerda. Em tempo de globalismo, no qual seus ideólogos não se cansam em afirmar que todos os países estão submetidos a uma "camisa de forças", não tendo alternativa senão seguir o modelo neoliberal americano $^{24}$, os trabalhistas britânicos fizeram o caminho inverso: estabeleceram o salário mínimo, tornaram os impostos mais progressivos e aumentaram em cinco pontos percentuais o gasto em educação e saúde, enquanto apresentavam excelente desempenho econômico ${ }^{25}$ '. Com isso, melhorou a distribuição de renda. E o capitalismo britânico, desde Thatcher identificado com o sistema americano, se aproximou do modelo renano ao invés de afastar-se dele, como prediz a tese do caminho único ${ }^{26}$.

\section{POVO E SOCIEDADE CIVIL}

O governo de esquerda em países capitalistas é, portanto, viável. As experiências européias não deixam dúvida a esse respeito. Por quê, então, no Brasil não tem sido viável, ainda que os eleitores elejam candidatos de esquerda ou, pelo menos, com discurso de esquerda? A resposta mais geral a essa questão está no fato de que como nos demais países em desenvolvimento, há aqui grande descompasso entreo "povo" ea "sociedade civil”, e é nesta última que sempre está o verdadeiro poder político nas democracias. Coloquei as duas expressões entre aspas, porque estou usando-as em sentido muito preciso: povo, aqui, é o conjunto de cidadãos iguais perante a lei, dotados do direito de voto; sociedade civiléesse povo no qual, porém, o poder de cada cidadão é ponderado pelo dinheiro, pelo conhecimento e pela capacidade de organização. Não estou, portanto, confundindo sociedade civil, conceito clássico, com "organizações da sociedade civil", principalmente organizações públicas não estatais de advocacia políticas - as chamadas organizações não governamentais stricto senso - , base da lenta transição das atuais democracias de opinião pública para as democracias participativas. Enquanto o conceito de organizações da sociedade civil permite o desenvolvi-
[22] Terceira via foi uma expressão utilizada durante muito tempo, em especial por autores católicos, para sugerir que haveria uma terceira possibilidade em relação ao conflito entre capitalismo e socialismo. A terceira via britânica não tinha essa pretensão, pretendia ser apenas uma forma de manifestação da socialdemocracia ou, mais precisamente, do social-liberalismo: a socialdemocracia, que, embora garantindo os direitos sociais, usa mais os mecanismos de mercado, inclusive no oferecimento de serviços sociais e científicos, tornando assim mais eficiente o aparelho do Estado.

[23] Giddens, Anthony. Beyond left and right. Cambridge: Polity Press, 1994; The third way and its critics. Cambridge: Polity Press, 2000; e Giddens, Anthony (org). The global third way debate. Cambridge: Polity Press, 2001.

[24] Thomas Friedman (The lexus and the olive tree. 2 ed. Nova York: Random House, 2000) não tem dúvida em usar a expressão straight-jacket para argumentar que só existe uma forma possivel de capitalismo eficiente: a americana.

[25] França, Alemanha e Itália apresentaram desempenho pior por motivos diversos. A meu ver, não foi por terem deixado de reduzir a proteção ao trabalho, como insiste a direita, mas por não terem feito a reforma da gestão pública ou reforma gerencial do Estado, no qual a Grã-Bretanha foi pioneira.

[26] Pearce, Nick e Dickson, Mike. "New model welfare". Prospect, no 10, maio 2005, pp. 20-21. 
[27] Esse conceito de sociedade civil, porém, foi muito útil para a análise que fiz, na segunda metade dos anos 1970, da transição democrática que então começava.

[28] Ver excelente resenha do debate sobre as organizações da sociedade civil que surgiram como alternativa emancipadora nos anos 1990: Lavalle, Adrián Gurza. "Sem pena nem glória: o debate sobre a sociedade civil nos anos 1990 ". Novos Estudos, n 66, pp. 91-109, julho 2003. mento de uma teoria de emancipação social por meio da emergência da democracia participativa ou da democracia deliberativa, o conceito de sociedade civil não tem caráter normativo ${ }^{27}$. Sugere apenas que a sociedade politicamente organizada — ou seja, a sociedade civil — tende a ser mais conservadora. E talvez menos democrática que o povo, porque aqueles indivíduos que possuem mais capital, mais conhecimento técnico, organizacional e comunicativo - e estão inseridos em organizações, sejam elas corporativas ou públicas não-estatais - terão individualmente mais poder que os cidadãos comuns.

Quanto mais avançada uma democracia, mais democratizada sua sociedade civil; por isso mesmo, menor será a diferença entre ela e o povo $^{28}$. Enquanto, em uma sociedade civil autoritária, ela própria não se distingue com clareza do conceito de elites, a distinção é clara no caso de sociedades civis democráticas. Entende-se aqui por sociedade civil mais democrática exatamente aquela na qual é menor a diferença de poder de seus participantes em relação ao poder de cada cidadão no povo. Ora, isso acontecerá na medida em que, em cada sociedade, aumentar o grau de igualdade de renda, conhecimento, capacidade de organização e, portanto, de poder político real. Ou seja, quando aumentar o grau de justiça social existente nessa sociedade. Dessa forma, embora liberdade, garantida pela democracia, e justiça, trazida pelo crescente respeito aos direitos sociais, sejam objetivos políticos independentes, a teoria política indica que afinal eles são também interdependentes quando pensamos em termos de graus de liberdade e em graus de justiça. Em sociedades como a sueca, ou a suíça, nas quais as desigualdades são relativamente pequenas, a sociedade civilé fortemente democrática, diferenciando-se pouco do povo. Assim, nessas sociedades, uma vez eleito pelo povo, um governo de esquerda - que afinal reflete o poder da sociedade civil — fará uma administração de esquerda.

Enquanto isso, em sociedades menos democráticas e menos justas, como as latino-americanas, o descompasso entre povo e sociedade civil é enorme. O povo não tende necessariamente a ser mais democrático que a sociedade civil, como bem mostram as pesquisas sobre o tema realizadas por entidades como o Latinobarómetro, mas tende a ser mais de esquerda, na medida em que demanda do Estado políticas ativas mais distributivas. Dado esse descompasso, uma vez eleito um governo de esquerda, a tendência dos novos governantes para alcançar 'legitimidade' política na sociedade civil será identificar-se rapidamente com as percepções e os valores centrais dessa sociedade, queéa fonte real de legitimidade. A fonte da legalidade política, nas democracias, é sempreo povo, porém a da legitimidadeé dada antes pelo apoio da sociedade civil. Observe-se que essa afirmação, como quase todas as demais que fiz neste texto, obedece a um critério antes histórico que normativo. Do ponto de vista normativo, seria melhor que legitimidade e legalidade se confundissem, mas nesse caso bastaria apenas um conceito. Por isso, ea 
partir de Weber, uso o conceito de legitimidade para indicar o fato de que um governo conta com o apoio da sociedade civil, enquanto emprego o conceito de legalidade para dizer que foi eleito regularmente pelo povo. $\mathrm{O}$ primeiro é um conceito real — sociológico e histórico -, o segundo é um conceito formal - jurídico, no sentido estrito dessa palavra. No governo recém-eleito, há tendência de a legalidade e a legitimidade política coincidirem, mesmo que o governo eleito seja de esquerda e não tenha contado com o apoio da sociedade civil na eleição. Isso porque, eleito o novo governo, a sociedade civil tenderá a dar um voto de confiança aos novos governantes. Entretanto, a sociedade civil, e sobretudo seus componentes mais à direita, esperam que o novo governo, ainda que conservando uma retórica de esquerda, revele rapidamente seu respeito pela propriedade e pelos contratos - pela ordem estabelecida, portanto -, e que não adote políticas redistributivas fortes. Caso contrário, o governo correrá o risco de perder seu apoio.

Foi o que aconteceu no Brasil, logo após a eleição de Luiz Inácio Lula da Silva no final de 2002 . O governo contou com essa boa vontade inicial das elites, e para conservá-la tratou de conformar-se quase integralmente a essa vontade. No plano da política econômica, em especial, no qual os interesses da direita rentista e financeira eram muito grandes, a conformidade foi total e permanente. Com isso, o governo deixou de ser de esquerda. Atendeu a interesses da classe média profissional maioria dos integrantes do PT - realizando uma ocupação de cargos públicos antes reservados à burocracia profissional do Estado. Esse "aparelhamento" do Estado, porém, não é uma política de esquerda, e sim apenas uma forma de corporativismo ou clientelismo. Contudo, com a estratégia de conformidade, nos primeiros dois anos o governo logrou não apenas acalmar os mercados financeiros, que estavam em crise no momento da eleição, mas manter durante esse período o apoio da sociedade civil. Perdeu-o apenas no terceiro ano, em função das denúncias de corrupção então surgirdas. Foi só a partir desse momento que o governo Lula perdeu legitimidade, embora conservasse a legalidade, e por isso paralisou-se.

O descompasso entre uma sociedade civil mais conservadora e um povo que - não obstante o autoritarismo de que é vítima — vota em candidatos de esquerda, explica, portanto, por que no Brasil a esquerda tende a ganhar as eleições mas afinal não governa. O sistema de incentivos existente em uma sociedade como essa leva à infidelidade dos políticos a seus comprometimentos. Há outras razões que explicam por que a esquerda tem dificuldade de governar em um país como o Brasil. Já me referi ao caso da extrema esquerda, cuja incapacidade de governar o capitalismo é auto-explicativa. Em todos os países temos também uma esquerda utópica, cuja opção por não ser governo é explícita, prefere, ao contrário, conservar o papel de crítica do governo. Em um caso como esse, porém, a pergunta central deste trabalho não se aplica. 
Ficando, porém, apenas com os partidos políticos de esquerda que querem governar na democracia, a pergunta seguinte ao que foi exposto até aqui é saber se, dado o descompasso existente no Brasil entre povo e sociedade civil, é inevitável que os partidos ou coalizões de esquerda, uma vez eleitos, não façam governos de esquerda. Não creio. Certamente os partidos de esquerda vitoriosos terão que fazer compromissos - afinal, a política é a arte do compromisso. Certamente não realizarão tudo o que seu programa prevê, ou mesmo o que foi prometido nas eleições isso sempre acontece nas democracias, com partidos de qualquer orientação. Mas eu acredito que, em um país capitalista de desenvolvimento médio como Brasil,é possível haver governos de esquerda.

O queé preciso para isso? A meu ver, duas coisas: espírito republicano e habilidade política. É essencial ou espírito ou a virtude republicana. Não vou discutir aqui se é viável ou não. No contexto desse trabalho, suponho que sim, com base na referida existência de dois (e não um só) instintos humanos básicos: o da sobrevivência e o da convivência. Considerando essa possibilidade como pressuposta, entendo por republicano o político ou o partido político que, em alguns momentos, arrisca perder o apoio de seus eleitores para agir de acordo com suas convicções do que seja o interesse público. Seus apoiadores políticos querem algo contrário ao que o político julga ser o interesse nacional. Não importam as razões de uns ou do outro. O importanteé haver divergência. Se o político tem a coragem necessária para arriscar sua reeleição, agindo de acordo com suas convicções, será republicano, e seu republicanismo poderá ser uma saída para o paradoxo da esquerda no Brasil.

Não basta, porém, espírito republicano. É preciso também competência política. A política é uma arte na qual não valem apenas princípios éticos e boas intenções. Vale também a habilidade de fazer compromissos e argumentar para alcançar maioria. Porque, afinal, a política não é outra coisa senão a arte do compromisso e da argumentação. É o exercício da prudência, na perspectiva de Aristóteles; é a busca do bem comum, na perspectiva tomista e lockiana; é a virtù do governante na busca dos objetivos republicanos, na visão de Maquiavel; é o exercício da ética da responsabilidade, na forma de ver a política de Max Weber. Não é, portanto, tarefa fácil. No entanto, essas qualidades e responsabilidades da política, que a fazem a mais nobre das profissões, não estão limitadas aos políticos de esquerda. Com freqüência também são observadas em políticos conservadores, os quais, porém, não enfrentam as contradições enfrentadas por políticos de esquerda. Por isso, para estes a tarefa é mais difícil, por isso seu espírito republicano tem que ser mais forte, por isso sua habilidade política é mais necessária.

Quando vemos a esquerda no Brasil curvar-se a uma sociedade civil queé principalmente de direita eque se apóia em um sistema internacio- 
nal cujos interesses são contrários aos do país, só podemos explicar o fato pela força dessas elites conservadoras. É preciso, entretanto, não limitar a análise e reconhecer que há também falta gritante de espírito republicano e de competência política. Ambos faltaram ao PSDB, e faltaram em maior grau ao PT. Segundo palavras de Tales Ab'Sáber, em um debate público, no caso do PT houve "descolamento da política do espaço social ainda mais radical do que já é; a política se autonomiza, se transforma em um grande balcão de negócios" 29 . Esse descolamento ou descompasso, nesse caso, se aprofundou porque o PT, embora tivesse expectativa de ocupação a longo prazo do poder político (como o PSDB tivera antes), não foi capaz de fazer a crítica do corporativismo que está em suas origens sindicais. Um líder sindical é legitimamente corporativista: seu papel é defender os interesses dos associados, do grupo econômico que representa. Um político, porém, não pode ser corporativista. De acordo com a ética da política que hoje prevalece nas sociedades democráticas, ele deve, em princípio, ser republicano, distinguindo os interesses próprios, e também os interesses daqueles que representa diretamente, dos interesses nacionais. O PT, como partido de origem sindical, nunca foi capaz de fazer essa distinção, e também por esse motivo não foi capaz de enfrentar o poder das elites no seio da sociedade civil brasileira. Nas palavras de Marcos Nobre, presente no mesmo debate citado acima, o PT geriu o governo como se fosse um partido, e geriu um partido como se fosse um sindicato. Além disso, salientou Nobre, faltou ao governo do PT capacidade para oferecer ao país uma alternativa de política não apenas econômica, mas também social: a crise acontece "porque não se consegue de fato mobilizar um discurso político e estabelecer um modelo político para o Brasil"30. Ao fazer essas afirmações, ele volta ao problema do descompasso entre o povo e a sociedade civil brasileira.

Apesar da gravidade da crise por que vem passando o PT e o governo Lula, que por certo desgastou-o profundamente, tem razão Sader quando critica a tentativa de "desqualificar o arcabouço histórico da esquerda, responsável pelos melhores momentos da história da humanidade, em nome de comportamentos que significaram o abandono desses valores e a adoção de métodos e políticas de direita"31. Fabiano Santos, no mesmo debate, defendeu a tese de que, apesar da crise, o PT continua a ser "o representante da socialdemocracia no Brasil" 32 . Tenho feito muitas vezes afirmação semelhante. Embora não seja impossível, a hipótese de o PSDB preencher esse papel continua remota, dados os apoios com que o partido conta. Como continua incerta a possibilidade deo PSDB dar um passo adiante e tornar-se um partido social-liberal. A possibilidade de surgir um novo partido de esquerda mais capaz de governar tampouco parece provável. O efeito maior da crise política foi enfraquecer o PT, mas não o levou ao esfacelamento. Os resultados das eleições presidenciais de 2006 são agora incertos, porém é provável que o Parlamento tenha novamente uma maioria de esquerda. Em qualquer
[29] Ab'Sáber, Tales. Declarações em debate sobre o PT promovido pela Folha de S.Paulo em 13/10/05. Resumo publicado na edição de 18/10/05.

[30] Nobre, Marcos. Declarações em debate sobre o PT promovido pela Folha de S.Paulo em 23/10/05. Resumo publicado na edição de 18/10/05.

\footnotetext{
[31] Sader, Emir. "PT, direita e esquerda". Folha de S.Paulo, 13/10/05, p.3.

[32] Santos, Fabiano. Declarações em debate sobre o PT promovido pela Folha de S.Paulo. Resumo publicado na edição de 18/10/05.
} 
Recebido para publicação

em 15 de janeiro de 2006.

NOVOS ESTUDOS

CEBRAP

74 , março 2006

pp. $25-45$ hipótese, nada sugere que a curto prazo o paradoxo da esquerda no Brasil encontre solução: o povo continuará votando na esquerda, mas ela não governará.

LUiz CARLos BREsSer-Pereira é professor da Fundação Getúlio Vargas de São Paulo. 